Artigo Original

\title{
O movimento como tema gerador para a prática pedagógica inter/trans/multidisciplinar
}

\author{
Ana Claudia de Melo Sanches ${ }^{1}$ \\ Edrick José lketani da Costa ${ }^{2}$ \\ ${ }^{1}$ Faculdade Ipiranga, FIPI, Belém, PA, Brasil \\ ${ }^{2}$ Professor de Educação Física da Rede Pública do Estado do Pará, Belém, PA, Brasil
}

\begin{abstract}
Resumo: Neste texto, Vivemos atualmente uma crise paradigmática no campo das ciências e que aos poucos a vemos tomar conta de nossa educação. Tal crise veio a inquietar-nos no sentido de como vemos o mundo, a ciência, a experiência e principalmente a educação. Notoriamente ela nos mostrou o quanto reduzimos a realidade, a cognição e, pior, o Homem em partes dissecadas sem ao menos um vestígio de vida. Nessa problemática, autores como: Moscovici, Merleau-Ponty (1999), Capra e Moreira se esmeraram a entender as partes a partir do todo e o todo a partir das partes num movimento complexo e sistêmico. Mostraram o quanto a ciência clássica limitava explicações de sistemas vivos que por serem vivos apresentam complexidades. Identificaram os obstáculos conceituais e de aprendizagem que foi atribuído a:o corpo, ao movimento humano, isto é, a motricidade humana.
\end{abstract}

Palavras-chave: Motricidade. Mapas conceituais. Prática pedagógica.

\section{The movement as a theme to the teaching practice inter / trans / multidisciplinary}

\begin{abstract}
We live today a paradigm crisis in the sciences and to see that slowly take over our education. This crisis came to disturb us in the sense we see the world, science, experience and especially education. Usually she showed us how much we reduce the reality, cognition, and the worst of it is that dissecting the human body in parts without even a trace of life. In this issue authors as Moscovici, Merleau-Ponty (1999), and Moreira Capra went to great pains to understand the parts from the whole and the whole from the parts in a complex and systemic movement. Showed how classical science limited explanations of living systems because they are living present complexities. Identified conceptual obstacles and learning that was attributed to: the body, human motion, ie, the human movement.
\end{abstract}

Key Words: Motricity. Concept maps. teaching practice.

\section{Primeiros Passos}

Nós da Escola Ignácio Koury Gabriel Neto procuramos desenvolver no ano de 2009 e antes do planejamento escolar, aquele cujo a maioria dos professores relutam em participar, a I Semana de Formação Continuada de Professores da escola, a qual tinha como objetivos envolver os professores nas discussões e reflexões sobre a prática pedagógica, planejamento, avaliação e iniciação científica para o Ensino Médio. Uma vez que a quase todo momento a qualificação do profissional da Educação Básica é posta em xeque pela sociedade e por nossas políticas, portanto vivemos num cenário de constantes desafios e incertezas ao trabalho docente que requer realização de estudos, pesquisas e formações continuadas para superação dos obstáculos encontrados na prática pedagógica de professores.

Tendo o pressuposto acima, assumimos os objetivos também das Diretrizes Nacionais de Formação de Professores para essa superação, envolvendo os professores nos objetivos abaixo relacionados: $\checkmark$ orientar e mediar o ensino para a aprendizagem dos alunos;

$\checkmark$ comprometer-se com o sucesso da aprendizagem dos alunos;

$\checkmark$ assumir e saber lidar com a diversidade existente entre os alunos;

$\checkmark$ incentivar atividades de enriquecimento cultural;

$\checkmark$ desenvolver práticas investigativas;

$\checkmark$ elaborar e executar projetos para desenvolver conteúdos curriculares;

$\checkmark \quad$ utilizar novas metodologias, estratégias e materiais de apoio;

$\checkmark$ desenvolver hábitos de colaboração e trabalho em equipe.

Sabemos que em uma Semana seria impossível alcançar todos os resultados promulgados pelas Diretrizes, no entanto procuramos deixá-los como desafios a reflexão.

O texto aqui escrito se subdividirá em três elementos chaves discutidos e observados em meio a Semana: a) A formação, a prática docente e as novas metodologias; b) Mapas conceituais 
como ferramenta de construção de aulas inter e pluridisciplinares; c) O movimento Humano como tema gerador de projetos pluridisciplinares. Por fim apresentaremos nossas considerações finais;

\section{a) A formação, a prática docente e as novas metodologias:}

Geralmente a prática docente ou a experiência docente se constrói sobre um terreno movediço, no qual muitas (in) seguranças e (in) determinações, outrora absolutas e obsoletas e outra relativas e contemporâneas se fazem a única verdade, na qual muitos profissionais iniciantes se agarram.

Partindo desse pressuposto pudemos rever não de forma atemporal e nem a histórica, a trajetória ou memórias, quanto, professores do Ensino Médio, uma vez que ouvimos relatos de reflexões sobre a docência, novas metodologias educacionais e principalmente sobre mapas conceituais (neste caso o movimento humano como tema gerador) como ferramenta para a construção do planejamento anual, de projetos inter e pluridisciplinares, bem como para os de iniciação científica.

Nessa relação de vai-e-vem entre o passado e o presente compreendemos e percebemos as angústias da profissão docente, destacamos que a maioria dos professores da escola são recémconcursados, e suas vozes delatam expectativas de que a Academia Ihes ensinaria ou transmitiria segurança obrigatória quanto ao ato de ensinar e de lidar com as intersubjetividades presentes nesse espaço. $\mathrm{O}$ avançar e retornar na formação e principalmente na percepção quanto profissionais incompletos e cheios de angústias os fez estar receptivos as propostas de formação.

Apoiados nesses avanços e retornos ao passado eles começaram a questionar como poderiam melhorar 0 processo ensinoaprendizagem. Como poderiam oferecer uma "ajuda ajustada" (ONRUBIA, 1998) para o processo de aprendizagem significativa e real para os mesmos, assim como, oferecer aprendizagem mútua sob a perspectiva de uma formação construtora e significativa, entre professor-aluno; aluno-professor; professorprofessor; aluno-aluno; etc.

Mas é importante salientar que todo caminho de formação profissional docente percorre trilhos em declives, que podem nos oferecer grandes oportunidades de desenvolvimento profissional e também resistências profissionais e identitárias. Entretanto observamos que a maioria deles assumiram a oportunidade de mudanças, isso foi observado mediante a uma postura de autonomia e de reflexão, daqueles que lidam diretamente com o ensino, nesse caso: os professores. Além dos textos avaliativos que cada um escreveu sobre a semana de formação.
A relação pedagógica que se tinha com a formação de professores para educação básica, e em específico os de licenciatura (experiência própria) perpassava pela concepção técnica e hiperespecializada destinada aos profissionais da educação de tempo atrás. Apesar de muitos professores tiveram contato com idéias reflexivas e significativas a educação, muitos repetiam em suas ações docentes o saber da Tradição pedagógica para ensinar (FIORENTINI, 1999). Partindo dessa constatação podemos inferir que essa mesma tradição impregnou muitos profissionais da a tradição pedagógica da racionalidade técnica (SCHÖN, 2000). Neste sentido é que enfatizamos a importância do vai-evem no presente e no passado com 0 intuito latente de refletir e agir na ação e decidir na própria formação.

Mas o que seria preciso para que um professor tome a sua experiência docente (sendo primeiros erros ou não) como fonte de investigação e a torne mola propulsora de mudanças no ensino e propulsora de autonomia para os seus alunos?

Longe de dar respostas "verdadeiras e absolutas", foi o propósito deste texto. Por isso que o mesmo procurou analisar de forma empírica o quanto uma formação, nada autônoma e acrítica pode interferir no desenvolvimento de pessoas e profissionais com altas probabilidades de reflexões e de mudanças. Por isso que a semana de formação continuada da Escola Ignácio Koury Gabriel Neto nos proporcionou alguns indicadores para a análise.

\section{b) Mapas conceituais como ferramenta de construção de aulas inter e pluridisciplinares:}

Pareceu-nos que não seria novidade aos professores o conceito de mapas conceituais, mas estávamos enganados! Para muitos o conceito e a construção do mesmo era algo novo. Por isso acreditamos ser relevante apresentarmos alguns posicionamentos referentes aos mesmos ao leitor.

Os mapas conceituais foram baseados a partir da teoria de aprendizagem significativa de David Ausubel. Para o estudioso em questão, para ocorrer a aprendizagem significativa aos alunos as aulas não deveriam ser mecânicas. Isto significa que o professor que é agente mediador do conhecimento deveria trabalhar o conhecimento prévio através de interações com o conhecimento científico, para favorecer a modificação do conhecimento preexistente e os conceitos escolares, fazendo com que ambos conhecimentos se modifiquem, assim tornando-se uma aprendizagem significativa.

Uma vez que a racionalidade clássica distanciou o conhecimento comum do conhecimento científico, pensando que o primeiro 
iria bloquear totalmente a introdução do indivíduo ao "mundo científico". Entretanto em estudos atuais e também não tão recentes provaram que esta dicotomia não ajuda em nada, já que mais uma vez estaríamos reduzindo a complexidade da existência humana em simples partes científicas.

Então, Onde ficaria a afetividade? A motricidade humana? A percepção de mundo e de Homem? As diversas formas de expressão? E como estas poderiam ou podem influenciar na construção de conceitos? De mapas conceituais?

Uma das grandes habilidades humanas é sem dúvida a linguagem articulada com significado. Essa possibilidade garantiu ao homem sair das amarras da experiência sensível alcançando níveis cada vez mais complexos de comunicação simbólica.

A pesquisa histórica sobre formação de conceitos vincula-se hoje na atualidade a uma tradição Roschiana: Eleonor Rosch, antropóloga e psicóloga norte-americana. Para a autora podemos observar a história das investigações sobre conceitos em três períodos: i) período da Concepção Clássica que vai desde Aristóteles até a década de 70 do Século $X X$; ii) Da década de 70 até 1985 onde predomina a Concepção Prototípica chamada também Probabilística e, iii) De 1985 em diante, a Concepção Teórica.

A concepção clássica tem uma natureza binária do tipo "tudo ou nada" um conceito de designação absoluta e uma classificação hierarquizada, onde os traços são generalizados de forma crescente até chegar ao limite de sua generalização, ou seja, o ápice.

A taxonomia aristotélica, apesar de trazer para sua época grandes contribuições, não contemplava a teoria do desenvolvimento de conceitos, sofrendo assim várias críticas em relação a sua forma generalizada de representar o real.

Segundo Oliveira (1999) uma característica da construção clássica é de considerar o conceito como conjunto de atributos ou propriedades individualmente necessárias e suficientes para os objetos do mundo real serem designados. Significando que para se ter um conceito uma entidade deve possuir cada uma das propriedades que as constituem e todas as propriedades têm que ser suficiente para que a entidade seja um exemplar do conceito.

\section{Exemplo:}

"Se animal e racional são as propriedades que compõem o conceito de homem, então, para que uma entidade seja um homem, é necessário que seja animal e que seja racional; conversamente se uma entidade é animal e racional, isso é suficiente para que seja um homem" (Oliveira: 1999, 18) [grifo nosso]

Já a concepção prototípica apoiada nas observações de Wittgenstein. Na nota 66 das investigações filosóficas considera que não existe uma características comum a todos os objetos que pertencem uma mesma classificação taxonômica. Esse autor introduz uma noção de famílias, onde há semelhanças que surgem e desaparecem diferentemente dos conceitos aristotélicos onde os conceitos se sobressaíam a partir de traços visíveis dos objetos.

Para ilustrar a critica aos conceitos clássicos aristotélicos. Wittgenstein relata uma reflexão sobre o conceito de jogos, que influenciará as pesquisas da década de 80 de Rosch e a qual descreveremos a seguir:

Considere, por exemplo, os procedimentos que chamamos de "jogos". Refiro-me a jogos de tabuleiro, jogos de cartas, jogos de bola, jogos olímpicos, etc. O que é comum a todos eles? Não diga "algo deve ser comum a todos eles, senão não se chamariam 'jogos'" - mas olhe se há algo comum a todos eles. Pois, se você os contempla não verá com efeito algo que seja comum a todos, mas verá semelhanças, afinidades, na verdade, toda uma serie delas. Como disse: não pense, mas olhe! - Olhe, por exemplo, os jogos de tabuleiro, com suas múltiplas afinidades. Agora passe para os jogos de cartas: aqui você encontra muitas correspondências com aqueles da primeira classe, mas muitos traços comuns desaparecem, e outros surgem. Se passarmos agora aos jogos de bola, muita coisa comum se conserva, mais muitas se perdem. - São todos "recreativos"? Compare o xadrez com o jogo da amarelinha. Ou há em todos um ganhar e perder, ou competição entre os jogadores? Pense no jogo de paciência. Nos jogos de bola há um ganhar e perder; mas se uma criança atira a bola na parede e a apanha outra vez, este traço desapareceu. Olhe que papeis desempenham a habilidade e a sorte. E como é diferente a habilidade no xadrez e no tênis. Pense agora nos brinquedos de roda: 0 elemento de recreação esta presente, mas quantos dos outros traços característicos desapareceram! E assim podemos percorrer muitos, muitos outros grupos de jogos e ver semelhanças surgirem e desaparecerem. (Ibidem, p.20)

Para a concepção Teórica "um conceito é constituído não apenas de propriedades, mas também de relações com outros conceitos. Os conjuntos dessas relações que articulam os conceitos entre si formam redes, as quais são vistas como teorias. Por 'teorias', neste contexto, deve-se entender não apenas teorias cientificas, mas também estruturas cognitivas do senso comum". (Ibidem, p.26)

Nesta perspectiva, um conceito não está fechado em traços comuns como na concepção aristotélica. E também não oscila numa concepção de semelhanças familiares onde as características surgem e desaparecem do objeto, articuladas por Wittgenstein.

Em relação a redes de conhecimentos temos por ponto de vista que estas ligações sistêmicas 
proporcionam o rompimento dos obstáculos epistemológicos e pedagógicos apresentados pelos indivíduos envolvidos num processo de crescimento. Isto significa que um conceito só ganha significado numa rede de relações teóricas, onde os conceitos científicos e os conceitos cotidianos se articulam dando um novo significado. Aí emerge o paradigma da mudança conceitual, tanto na educação de crianças quanto na educação de adultos.

Santos (1991), observa existirem dois macros modelos de pesquisa de formação de conceitos: a) Modelo de Aquisição Conceitual e b)Modelo de Mudança Conceitual. O primeiro modelo de aprendizagem conceitual não considera as interações que ocorrem entre os sujeitos e entre idéias. $O$ conhecimento é transmitido pelo professor, centra-se no conteúdo, menosprezando a natureza e origem do conhecimento. Um conhecimento que e adicionado do mundo externo e que irá compor o mundo interno do sujeito. Santos \& Cruz apud Santos (1991: p. 175), defendem: I) 0 conhecimento cresce por acumulação aditivada, ou melhor, que a aprendizagem conceitual se faz atomisticamente por ordenação e associação dos conceitos um a um (disposição em camadas hierárquicas sucessivas); II) a experiência, origem de todo conhecimento, é dada em fragmentos referidos a dados dos sentidos; III) a informação recebida á da mesma natureza da informação transmitida; IV) indivíduos diferentes adquirem concepções idênticas a partir da mesma informação; V) o aluno, receptáculo passivo da informação, guarda as concepções substancialmente intactas e etc.

Para o Modelo de Mudança Conceitual a questão que se coloca é "como mudam os conceitos sob o impacto de novas idéias ou de novas evidencias?". Já que o aluno não é uma Tabula Rasa, pois chega a escola com suas concepções de mundo, de objeto, de homem etc. que muitas vezes funcionam, como crenças, tão rígidas, que o processo de mudança conceitual requer um desestruturação em toda uma rede funcional, com a qual opera sua cognição.

\begin{abstract}
"O conhecimento constrói-se por reestruturações sucessivas. Contudo, a mudança não é nada fácil. Qualquer idéia esta articulada de uma forma complexa a muitas outras idéias. Por conseguinte, mudar uma, implica, muitas vezes, repensar outras. O conhecimento individual não é um conjunto discreto de elementos, mas antes uma serie de estruturas. A aprendizagem envolve 0 desenvolvimento e a mudança de tais estruturas. Como adverte Stenhouse (1986), embora o problema de saber como ocorrem as mudanças conceptuais esteja a ser alvo de muitas atenções, esta ainda longe de ser solucionado." Santos (1991: p.178)
\end{abstract}

É evidente, atualmente, que professores críticos trabalham formação de conceitos com que trabalha nos apoiaremos nas teorias de sócio-históricas para o qual o homem é fruto das interações sociais, e nas quais ele também faz parte. Portanto 0 desenvolvimento do Pensamento e da linguagem também o é, sendo assim os conceitos formados por nossas mentes humanas também os são.

Logo os professores participantes da formação são frutos das interações sociais, e que com eles trazem saberes experienciais estabelecidos ao longo de suas vidas, isto é, foram formados desde a sua infância e durante a sua fase adulta.

Segundo a teoria histórico-social há dois tipos de conceitos podem emergir ao longo do desenvolvimento humano, e que eles têm o poder de impregnar a formação de conceitos, ou não, tanto na criança quanto no adulto.

A primeira forma de conceito a desenvolver no Homem, seria de caráter espontâneo, este seria fruto direto das experiências dos sujeitos, este podendo ser chamado de Conceitos espontâneos ou Cotidianos. A segunda forma de conceito seria o Conceito Científico, o qual seria fruto de conhecimentos produzidos e sistematizados pela cultura.

Embora os conceitos científicos e espontâneos se desenvolvam em direções opostas, os doiș processos estão intimamente relacionados. É preciso que o desenvolvimento de um conceito espontâneo tenha alcançado um certo nível para que a criança possa absorver um conceito cientifico correlato. Por exemplo, os conceitos históricos só podem começar a se desenvolver quando os conceitos geográficos e sociológicos devem se desenvolver a partir do esquema simples 'aqui e em outro lugar'. Ao forçar a sua lenta trajetória para cima, um conceito cotidiano abre caminho para um conceito cientifico e o seu desenvolvimento descendente. Cria uma serie de estruturas necessárias para a evolução dos aspectos mais primitivos e elementares de um conceito espontâneos, que lhe dão corpo e vitalidade. Os conceitos científicos, por sua vez, fornecem estruturas para o desenvolvimento ascendente dos conceitos espontâneos da criança em relação à consciência e ao uso deliberado. Os conceitos científicos espontâneos desenvolvem-se para cima por meio dos conceitos científicos. (vygotsky, apud Oliveira, 1992)

Isto significa que o adulto precisou enquanto criança desenvolver seus conceitos cotidianos referentes a natureza do real, e que de certa forma ao procurar uma instituição de ensino formal, está a procura de ajustar ou até mesmo de modificar suas crenças dogmáticas do real através da aquisição, da intersubjetividade e também através da intra-subjetividade dos conhecimentos institucionais dos conhecimentos científicos. Sendo assim o homem como sujeito histórico e construtor de sua própria história entrará em conflito com os conhecimentos adquiridos pela a sua experiência e o provará através da relação como conhecimento abstrato, ou seja, mental. 


\section{Portanto:}

Tudo aquilo que sei do mundo, mesmo por ciência, eu sei a partir de visão minha ou de uma experiencia do mundo, sem a qual os símbolos da ciência não poderiam dizer nada. $O$ universo da ciência é construído sobre o mundo-vivido e, se queremos pensar a própria ciência com rigor, apreciar exatamente seu sentido e seu alcance, precisamos, primeiramente, despertar essa experiência do mundo da qual ela é a expressão segunda. (MERLEAU-PONTY, 1994, p. 3)

\section{Como se constroem os mapas conceituais? Quais condições necessárias para a aprendizagem significativa?}

Ausubel indicava a organização dos mapas na forma bidimensional, ou seja, organizando os conceitos não apenas verticalmente mas também horizontalmente. Com base no princípio de diferenciação progressiva, os conceitos mais gerais e inclusivos de uma matéria são retratados no topo, prosseguindose no sentido de cima para baixo, de maneira a indicar as relações de subordinação conceitual. Assim, conceitos mais englobantes ficam no topo, conceitos subordinados ficam num nível intermediário e conceitos específicos, de menor inclusão, são colocados na base. A diferenciação progressiva, para Ausubel, corresponde à seqüência natural da consciência humana quando esta é exposta a um campo novo do conhecimento. Quando os conceitos têm aproximadamente o mesmo nível de generalidade e inclusividade, figurarão lado a lado. Pelo princípio da reconciliação integrativa, parte-se da base para o topo. Os conceitos pouco inclusivos são recombinados de modo a explorar as relações que existem entre eles, percebendo semelhanças e diferenças, e passa-se a inserí-los em seus inclusores. Enquanto a diferenciação progressiva toma um caminho descendente, a partir do geral, a reconciliação integrativa toma um caminho ascendente, partindo de especificidades. (LEITE, 2002, p.p. 202-203)

Neste sentido a aprendizagem dos conhecimentos científicos poderiam apoiar-se em conhecimentos subsunçores para mediar a construção de novos conceitos. Favorecendo a organização desses conceitos por meio da própria auto-organização conceitual.

\section{c) O movimento Humano como tema gerador de projetos pluridisciplinares}

\section{Conhecimento subsunçor ou Tema gerador?}

Para se construir um mapa conceitual era necessário termos o conhecimento subsunçor para gerar um tema a ser discutido e organizado para o entendimento de mapas conceituais e também para a estruturação de um planejamento interdisciplinar. A inquietação do grupo coordenador era: como provocá-lo?

A partir dessa inquietação em grupo decidimos que o tema gerador poderia surgi de uma atividade lúdica para esse propósito. Inicialmente acreditamos que os nossos participantes iriam abordar a brincadeira como tema gerador. Entretanto eles nos surpreenderam ao apontar o movimento humano como tema gerador.

O movimento Humano como elemento gerador da construção do nosso mapa conceitual?

Essa percepção foi uma surpresa para nós, uma vez que o modelo de ciência clássica "retalhou" o Homem, o tornando partes, ao invés de todo. Dissecando-o, matando a essência, ao invés de compreender a vida que se faz presente neste ser e a complexidade que nela se faz presente. Supervalorizando a mente em detrimento do corpo.

Ao evidenciarem o movimento humano como tema gerador, os professores abriram caminho para o entendimento da motricidade humana. Já que :

A Motricidade Humana concebe o homem em todas as suas dimensões e na sua singularidade, e tem como princípio o transcender. O que está embutido na nomenclatura é o movimento humano histórico, cultural, que através da consciência corporal e do movimento intencional e não alienado, constrói a análise, a crítica, a cidadania.

(ARAGÃO, http://sol.ccsa.ufrn.br/gepem/porquemotricidade.ht m)

Através dessa percepção, iniciamos a construção dos mapas conceituais, a partir das reflexões dos professores presentes. Muitos (in)conscientes visualizaram que nenhuma das áreas de estudos para o Ensino Médio está desconectada. Observaram que é a partir de conexões inter e multidisciplinares que a aprendizagem poderá se tornar significativa.

A atividade desenvolvida com os professores em forma de brinquedo cantado foi objetivada com a proposta de estimular os professores a refletir sobre o lúdico sendo este feito pelo corpo humano, tendo em vista que a sociedade numa redução complexa é movida pela ação individual empregada no coletivo. Partindo desse pressuposto, observamos que os brinquedos cantados focaram o movimento do corpo de forma abrangente, onde no $1^{\circ}$ atividade cantando num determinado ritmo devia falar o movimento em musicalidade rítmica e aos mesmo tempo executá-lo sendo que o grupo teria que manter o compasso simbiótico no grupo, isto é mostrar interdependência do grupo e do individuo.

Não era permitido repetir o movimento do outro grupo rival nem o próprio de grupo, ganharia a equipe que não erra-se; no segundo jogo envolvendo movimento seriam uma atividade interdisciplinar onde pelo terreno eram subdividido um grupo menores com tarefas para serem executadas e não deveria ser respondida o que se pedia QUEM? (pergunta que remete dizem pessoa ou ser); COM QUEM?(pergunta que remete novamente pessoa mas dá idéia de 
pessoa ou ser mas fazendo companhia); FAZENDO OQUE?(PERGUNTA que expressa um ação seja no passado, no presente ou no futuro); ONDE? (Pergunta que remete a um luga), bom nesta o movimento desenvolvido está na codificação da idéia da linguagem, com o corpo, pois os envolvidos ao mesmo tempo devem imaginar a respostas dadas pelos outros grupos e tentar criar um coesão no texto?

A terceira atividade proposta mostrou que numa construção de uma história oral nos momentos em que se sucederiam. As palavras ônibus, passageiro e viagem representavam respectivamente um giro em torno de si, o bater palmas e a troca de lugares.

Destacamos o ônibus como movimento gira em torno do próprio eixo estando fixo na marca ao chão de um quadrado espaço destinado a cada um dos passageiros, que ao ouvirem na história a palavra todos deveriam girar no próprio eixo, em sentido horário e retornar ao mesmo local de origem, viagem como proposta a troca de lugares sem poder ser com amigo do lado dando preferência ao da frente.

Neste momento o contador da história ou o orientador da brincadeira quisesse escolher outro espaço, deveriam vir ao meio e entrar na marca fixa ao chão. No momento da historia em que se usava palavra viagem, o movimento desenvolvido proporcionou o entendimento de espaços numa perspectiva geográfica, pois requer conhecimento de sentido horário, desenvolve sentido orientação e percepção auditiva, além de se orientar geograficamente nos espaços experienciados.

"todas as manifestações de movimento corporal das quais o indivíduo pode formar uma representação psíquica, através de qualquer sistema de signos, e podem ser submetidas ao seu controle voluntário. Compreendida como processo em construção, cujas formas históricas se concretizam nas interações concretas do homem com a natureza e com outros homens, emerge nas suas diferentes manifestações como produto da interação dialética entre as propriedades biológicas do organismo e as práticas sociais que envolvem a ação de todas as instituições em seus aspectos ideológicos e materiais". (Kolyniak Filho citado por ARAGAO, ibiden).

É necessário destacar que as manifestações corporais expressas pelos professores participantes inicialmente se apresentaram tímidas e deslocadas, hipoteticamente, por considerarem a atividade lúdica corporal, "coisa de criança". Seus corpos resistiam aos comandos, como é que poderíamos saber disso? As expressões faciais tensas, braços cruzados e pernas tremendo a todo momento, foram alguns sinais importantes.

As manifestações corpóreas ocorrem em qualquer meio em que o homem esteja inserido.
Ás vezes de forma inconsciente, reprimida, outras condicionada, domesticada, poucas vezes intencional. O que é perceptível é que tais manifestações são expressões de vida, e de vida humana. Marta Genú Aragão http://sol.ccsa.ufrn.br/gepem/porquemotricidade.ht $\underline{\mathrm{m}}$

Ao solicitarmos que os professores refletissem sobre as atividades realizadas tendo como subsunçor o movimento humano as interações feitas foram inicialmente fragmentadas, evidenciando como ainda somos profissionalmente formados para o rex cogitans. A Academia nos orienta a sermos apenas parte e não um todo mais complexo.

Algumas pessoas podem achar que o que aconteceu não foi uma descoberta significativa, mas sim uma percepção corpórea, logo o movimento apresentou-se para os participantes como a argumentação mais lógica da essência humana. Já que cada sujeito -participante orientou a sua vontade e/ou percepção do que apreendeu a partir de sua compreensão de mundo.

Como todas as estruturas físicas, biológicas e de comunicação social se conectam e em conexões misteriosas para encher o ser humano de uma motrivivência cultural ${ }^{1}$

Ora para tomarmos consciência de si precisamos nos dar conta do nosso sistema complexo, de nossa auto-organização, da educação e da auto-educação, da construção complexa e sistêmica do ser bio-psíquico-social e motriz. Já que a quase a todo momento deixamos essa percepção nos escapar entre os dedos e ser dominada pela lógica reducionista das argumentações cartesianas.

Pode parecer estranho a determinadas pessoas que o movimento humano é conhecimento subsunçor elemento efetivo para a cognição de crianças, jovens, adultos e idosos.

Por isso acreditamos, sim, que o movimento humano foi redescoberto pelos professores em formação continuada e ao mesmo tempo elemento de percepção corporal e motriz para um dos maiores mistérios da vida a complexidade do movimento humano.

\section{Referências}

LURIA, A. R. Pensamento e linguagem: as ultimas conferencias de Luria. Porto Alegre: Ed. Artes médicas, 1986.

MERLEAU-PONTY, M. Fenomenologia da percepção. 2. ed. São Paulo: Martins Fontes, 1999.

1 Termo utilizado por COSTA, Edrick J. Iketani em artigo apresentado ao II Curso de Especialização em Lazer da Universidade do Estado d Pará - UEPA, sob orientação da Prof. Msc. Vera Lúcia Fernandes. 
MOREIRA, J. M. Desenvolvimento profissional dos professores: Acepções, concepções e implicações. (texto para discussão em sala do Programa de mestrado)

MOSCOVICI, F. Desenvolvimento interpessoal. $3^{\mathrm{a}}$ ed. Rio de janeiro: LTC, 1985. pp. 17-23.

MOURA, M. P. A organização Conceitual em Adultos pouco escolarizados. In: OLIVEIRA. Marcos Barbosa de \& OLIVEIRA, Marta Kohl de. Investigações cognitivas : conceitos, linguagem e cultura, Porto Alegre: Ed. Artes Medicas.1999. p. 101-113

OLIVEIRA, M. B. A tradição Roschiana. In: OLIVEIRA. Marcos Barbosa de \& OLIVEIRA, Marta Kohl de. Investigações cognitivas : conceitos, linguagem e cultura, Porto Alegre: Ed. Artes Medicas.1999. p. 17-33

\section{OLIVEIRA, M. K. Três questões sobre o}

Desenvolvimento Conceitual. In: OLIVEIRA. Marcos Barbosa de \& OLIVEIRA, Marta Kohl de. Investigações cognitivas : conceitos, linguagem e cultura, Porto Alegre: Ed. Artes Medicas.1999. p. 55-64

OLIVEIRA, M. K. Organização Conceitual e Escolarização. In: OLIVEIRA. Marcos Barbosa de \& OLIVEIRA, Marta Kohl de. Investigações cognitivas : conceitos, linguagem e cultura, Porto Alegre: Ed. Artes Medicas.1999. p. 81-99

SANTOS, M. E. V. M. Mudança Conceptual na Sala de Aula: Um desafio pedagógico. Livro horizonte: Lisboa, 1991.
Esse artigo foi apresentado em Sessão Temática no VI Congresso Internacional de Educação Física e Motricidade Humana e XII Simpósio Paulista de Educação Física, realizado pelo Departamento de Educação Física do IB/UNESP Rio Claro, SP de 30/4 a 03/5 de 2009.

\section{Endereço:}

Ana Claudia de Melo Sanches

Secretaria Administrativa de Educação do Pará.

Rodovia Augusto Montenegro, Km 10 Maguari

Belém PA Brasil

66130-000

e-mail: sanches.anaclaudia@gmail.com

Recebido em: 10 de fevereiro de 2009.

Aceito em: 03 de abril de 2009.

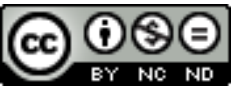

Motriz. Revista de Educação Física. UNESP, Rio Claro, SP, Brasil - elSSN: 1980-6574 - está licenciada sob Licenca Creative Commons 